\title{
Reflection in design education
}

\section{Louis Lousberg $^{1} \cdot$ Remon Rooij $^{1} \cdot$ Sylvia Jansen ${ }^{2} \cdot$ Elise van Dooren $^{1} \cdot$ John Heintz ${ }^{1}$. Engbert van der Zaag ${ }^{1}$}

Accepted: 19 June 2019 / Published online: 25 June 2019

(c) The Author(s) 2019

\begin{abstract}
In this article we evaluate the manner in which we at the Faculty of Architecture and the Built Environment at the Delft University of Technology encourage the development of the capacity of reflection among our undergraduate students. First we explore the concept of reflection in relation to respectively experiential/reflective learning, reflection in/on action, reflection in higher education and reflection in design education. Next we describe our research object, our Bachelor course in Academic Design Reflection. Two research questions are at hand: (1) does the level of reflection increase during our course and (2) Can the operationalisation in our questionnaire of the definitions of reflection derived from theory statistically be confirmed? We measured and processed statistically the level of reflection of 100 students in 3 of their papers on their design. Results show there is a significant slight increase of this level among the three papers. Results also show that our model of classification is not statistically confirmed in the data. We conclude with a discussion on the implications for further research and for design education.
\end{abstract}

Keywords Reflection $\cdot$ Learning Practice $\cdot$ Academic skills

Louis Lousberg

L.H.M.J.Lousberg@tudelft.nl

Remon Rooij

R.M.Rooij@tudelft.nl

Sylvia Jansen

S.J.T.Jansen@tudelft.nl

Elise van Dooren

E.J.G.C.vanDooren@tudelft.nl

John Heintz

J.L.Heintz@tudelft.nl

Engbert van der Zaag

E.J.vanderZaag@tudelft.nl

1 Faculty of Architecture and the Built Environment, TU Delft, Delft, The Netherlands

2 OTB Research for the Built Environment, Faculty of Architecture and the Built Environment, TU Delft, Delft, The Netherlands 


\section{Introduction}

'The first challenge for engineering education is to anticipate the capabilities our graduates will need in their future jobs' (Kamp 2016a, b: p. 12). Professionals with the combined skill of analysis and synthesis are becoming more and more pivotal in a complex and uncertain world, which asks for answers and solutions for today's and tomorrow's questions of sustainable and equitable (urban) development. To prepare engineers for their future jobs we need to emphasize not only the academic skills of analysis and research, but also, and more and more, the academic skills of synthesis (Kamp 2016a, b). In designing, reflection can be added to that as a third skill (cf. van Doorn 2004: p. 32; Boekholt 1984) Our proposition is that rigorous and thorough attention for reflection in design education plays a key role in developing these skills.

Contrary to reflection-in-learning in health professions (e.g. Mann et al. 2009) or higher education in general (e.g. Mittendorff 2014), little is known of reflection in design education, especially on the effectiveness of learning to reflect. Even though the importance of the development of a reflective practitioner is supported in the literature on (construction) projects (e.g. Ojiako et al. 2008; Sage et al. 2010). This article contributes to filling this knowledge gap.

Our research object is our third (and final) year Bachelor course in Academic Design Reflection at our Faculty of Architecture and the Built Environment at the Delft University of Technology. The objective of the research is to check if our course contributes to the development of the capacity of reflection among our undergraduate students. Two research questions are at hand: (1) does the level of reflection increase during our course and (2) Can the operationalisation in our questionnaire statistically confirm the definition of reflection derived from theory?

In the article we first explore the concept of reflection in learning (Kolb 1984; Moon 2004), in practice (Schön 1982; Moon 2004) and in higher education (Brockbank 1989; Fry et al. 2003; Cowan 2006). After presenting the case we next, based on the four levels of reflection developed by Moon (2004) — descriptive writing, descriptive reflection, dialogic reflection, critical reflection-evaluate the development of the level of reflection on design in papers of over a hundred of final year B.Sc. students in Architecture, Urbanism and Building Sciences (AUBS). Over a 10 week period, these students (about 150 two times per academic year) develop both an integral design for a museum and a series of four academic papers underpinning and evaluating (1) the design situation, (2) the design theme, (3) the design process and (4) the relation between design and academic research. From this evaluation we draw conclusions on the effectiveness of the reflection and derive implications for design education.

\section{Exploring reflection}

Since the early eighties of the last century reflection has become an issue in literature on professional education (e.g. Schön 1982). Depending on their underlying view reflection can be defined in different ways. Reflection can be seen as Dewey's (1933) 'thinking to encompass feelings and emotions in practice settings' (in: Boud and Garrick 1999: p. 4), as 'thinking about doing something while doing it' (Schön 1982: p. 54), as 'reflective learning' (Moon 2004: p. 80) or as 'a means to engage in making sense of experience 
in situations that are rich and complex and which do not lend themselves to being simplified by the use of concepts and frameworks that can be taught' (Boud and Garrick 1999: p. 4). Trying to be applicable to different context's these definitions are necessarily general. Within the context of reflection in design education in our course we define it for our students, close to the definition of Reflection (in Action) of Schön but broader, as 'thinking about your own work'.

\section{Experiential learning or reflective learning}

Departing from this 'thinking about your own work', for our students in AUBS it is thinking about your own design. Design is an object here (to think about), similar to experience as an object (to think about). This brings us to the theory of experiential learning as coined by Kolb (1984). Kolb defines experiential learning as 'the process whereby knowledge is created through the transformation of experience' (Kolb 1984: p. 38).

Moon (2004) distinguishes experiential learning from reflective learning. Reflection is 'a form of mental processing-like a form of thinking- that we may use to fulfil a purpose or to achieve some anticipated outcome or we may simply 'be reflective' and then an outcome can be unexpected.'(ibid: 82) and in an academic context 'reflection/reflective learning or reflective writing (-), is also likely to involve a conscious and stated purpose for the reflection, with an outcome specified in terms of learning, action or clarification. It may be preceded by a description of the purpose and/or subject matter of the reflection. The process and outcome of reflective work are most likely to be in a represented (e.g., written) form, to be seen by others and to be assessed (-). '(ibid: 83 ).

In literature several definitions of experiential learning are suggested for educational contexts; unanimity from this range of views is not possible. The root cause of this seems to be lying in the variety of views of experience (ibid: 109). Here, in our cause, the experience was the experience of design(ing). Hence we define experiential learning as 'a process in which an experience is reflected upon and then translated into concepts (-)' (ibid: 109), supported by the proposition that experiential learning in academic contexts seems to occur in situations wherein 'the material of learning is ill-structured and challenging to a learner' (ibid: 129), designing is exactly such a situation (Simon 1969).

The difference between experiential learning and reflective learning seems to be lying in an immediate reflection in experiential learning and a reflection afterwards in reflective learning in an academic context as Moon defined it. Because students in our course were not asked to record their findings immediately while designing, but to reflect afterwards, the concept of reflective learning is more appropriate in this case.

\section{Reflection in action or on action}

Similar to this distinction between experiential and reflective learning is the distinction between reflection-in-action (Schön 1982) and reflection-on-action (Schon 1987). Schön's in the architectural world well received work from 1982 'The reflective practitioner' describes based on only a few cases how professionals in general and architects in particular think while they do. Schön coins this as Reflection in Action (ibid: 54). He clearly distinguishes this from reflection-on-action that relates to the evaluation of the effects of the act according to predetermined goals (Schön 1987). Because we didn't ask students to record their thoughts while designing but immediately afterwards and taking Schön's distinction strictly, reflection-in-action is not applicable in our case but reflection-on-action is. 
Regarding this reflection-on-action as we applied in our case a distinction can be made between analytical reflection and evaluative reflection (Cowan 2006: p. 66, 81). Analytical reflection reflects on how e.g. things are done and evaluative reflection is 'a process which leads to the making of a judgement in relation to a set of values or criteria, and one in which the judgement often leads to a consequent decision' (ibid: 81). In this research paper 3 on the design process is an example of analytical and paper 4 an example of evaluative reflection. Although both types occur, they are not evaluated separately in this research.

\section{Reflection in higher education}

In literature on more or less similar courses as ours often no distinction is made between reflection-in-action and reflection-on-action. e.g. 'becoming a reflective practitioner' (Fry et al. 2003: p. 215 etc.) assumes that learning how to reflect on action or reflective learning as defined by Moon, will develop reflection-in-action. In literature courses are described that assume to develop reflective practice by letting the student use direct reflective dialogue (Schön 1982) as a start to develop reflection on a higher level. Reflective dialogue is characteristic for e.g. the design process wherein ill-structured problems are contextualised and framed in an 'inner dialogue' between the design as designed by the designer and the designers thoughts about this design. e.g. Brockbank et al. (1989) describe the process by which student learners engage in critically reflective learning through reflective dialogue. They lean heavily on the theory of singleand double loop learning as proposed by Argyris (1977), where single loop learning as 'instrumental learning which leaves underlying values and theories unchanged' can provoke double loop learning as 'learning where assumptions are challenged and underlying values are changed' by questioning these assumptions (Brockbank et al. 1989: p. $43,45)$. In our course we asked the students first to register their design decisions in a log called 'Design and Research-scheme' and base their afterwards written reflections on that scheme.

\section{Reflection in design education}

Design can be described as reflection in action (Schön 1983). This is confirmed by Roozenburg and Dorst (1998: p. 35) as they write 'modelling design as reflection in action works particularly well for conceptual stages in a design process'. As indicated above, according to Schön (1983) distinctions can be made between reflection-in- and reflection-on-action; but also between reflection on the design and reflection on the design process. Congruent with it in our course the students were asked in their paper 2 for the benefit of reflecting on the design to generate knowledge over a particular design theme based on scientific literature and in their paper 3 to reflect on their own design process on the basis of five generic elements of Van Dooren et al. (2014). Both kinds of reflection, reflection-in-action and reflection-on-action are believed to contribute to the level of doing while designing (Van Dooren et al. 2017), exactly the reason why we organize the course Academic Design Reflection for our undergraduate students. Also the reason why we would like to know if the level of reflection of the students is rising while following this course. Hence our first research question: Does the level of reflection increases during the course? 


\section{The cases}

Our course is the third 5EC course of a learning line called Academic Skills (AC; $3 \times 5 \mathrm{EC}$ ), consisting of a first year starting course in academic writing AC1, a second year Empirical Research Project AC2 and a third year course AC3 Academic Design Reflection. During the second and third year students are expected to use and deepen their acquired academic skills, such as academic writing, presenting, augmenting and underpinning, and evaluating and positioning in all kinds of design and research work in the other five learning lines: (1) Technology $(5 \times 5 E C)$, (2) Fundamentals $(4 \times 5 E C)$, (3) Society, Process and Practice $(3 \times 5 \mathrm{EC}),(4)$ Design $(6 \times 10 \mathrm{EC})$, and (5) Visualisation, Representation and Form $(3 \times 5 \mathrm{EC})$.

AC1 offers the student the overarching framework of how AUBS could be understood as a scientific discipline. In addition, the module provides very concrete academic skills, such as setting up and write a report of a literature review, the conventions of academic writing, searching in literature, presentation and debating skills. AC2 offers the student the knowledge and skills to an empirical research for the improvement of an existing design proposal to set up, perform, and report in a research report. The learning goal of AC3 is to relate research directly to design, and to take an argued position in this. AC3 Academic Design Reflection is a course that goes parallel to a 10EC design course, the sixth and final one before students can obtain their Bachelor degree. We explicitly work close together with the architectural supervisors and as a matter of fact we have the same groups of students that follow the design course in our group to teach them how to reflect in an academic way-that is using scientific knowledge and applying scientific ways of working- on their design. To reach the learning goal the student has to write 4 papers, one about the assignment, one about a self-chosen design theme, one on the design process and finally one on the relationship between design and research.

For instance and as indicated in "Reflection in design education" section, in the paper on the design process students use a framework particularly developed for making explicit in design education by Van Dooren et al. (2014). Van Dooren et al. provide an intermediate to make the communication between student and architectural supervisor about the students design effective. Key to this effectiveness is making things explicit. Based on research of the design process, on differences between novices and experts designers and on personal experience in design education practice, Van Dooren et al. have developed a conceptual framework consisting of five generic elements in the design process: (1) exploring and deciding, (2) guiding theme, (3) domains, (4) library of references, and (5) the design language. For the third paper in our research students were asked to reflect on their own design (process) based on these five elements.

\section{The method}

In the sequence of paper 1, 2, 3 and 4 we assume there is an increasing level of abstraction, hence in the level of reflection. To measure this level we adapted the four levels of reflection developed by Kember et al. (2000) and Moon (2004: p. 96, 97)—descriptive writing, descriptive reflection, dialogic reflection, critical reflection. See Fig. 1. To avoid misinterpretations we used a rather simple definition of academic reflection for the questionnaire: 'Academic reflection is to think about your own work with the use of scientific knowledge'. 


\section{Reflection Questionnaire*}

It is intended that the academic level of reflection of paper 2, 3 and 4 on the basis of the following questions is assessed; the questionnaire is thus three times followed by the assessor, per paper one time. It takes 1 to 1,5 minute per assessment. Plea se fill the appropriate circle in your degree of agreement with the statements: A—strongly agree $\mathrm{B}$ - more or less agree $\mathrm{C}$-more or less disagree D—strongly disagree.

\section{Definition of reflection}

Academic reflection is to think about your own work with the use of scientific knowledge.

\section{Habitual Action/Descriptive writing}

1. The paper leaves no evidence of reflection.

5. The paper is purely a description without a discussion of that description.

9. The paper follows what is required, but shows no thoughts about that

13. The paper is superficial.

\section{Understanding/Descriptive reflection}

2. The paper shows that the concepts of lectures, module manual and literature are understood.

6. There is an explanatory or descriptive reflection as opposed to a discussing one.

10. The possibility of alternative viewpoints is accepted, but most reflection is from one perspective

14. The concepts of lectures, module manual and literature are processed integrated into the paper; It is not a 'paste 'of those concepts in addition to the own language.

\section{Reflection/Dialogic reflection}

3. The paper shows a ' backtrack ' seeing events, actions or content which leads to a different level to clarify his/her dialogue with $\mathrm{him} /$ herself and a different level of the exploration of the discourse on events, actions or content.

7. There is a recognition that there are different reviews and alternative explanations may exist of the same material.

11. There is reflected to see if there can be learned

15. There is a discussion between multiple perspectives.

\section{Critical Reflection/Critical Reflection}

4. The paper shows a consciousness that acts and events are not only localized within and explainable by multiple perspectives, but that they are localized in and influenced by multiple historical and socio-political contexts.

8. The paper shows that previous assumptions or ideas are challenged *

12. The paper shows that there is a change of perspective.

16. On the basis of structured observations and literature an argued individual position is established.

* Parts in Italic originate from the questionnaire of Kember et al, 2000 ( 1 per level). The other are operationalis ations of definitions of levels of reflections by Moon, 2004, except question 6,15 and 16, which are based on the evaluation criteria for the learning objectives of the course. For the analyses, the answers to some questions have been recoded such that a higher value always refers to a higher level of reflection.

Fig. 1 The design of the questionnaire

As in the questionnaire of Kember et al. (2000) we mixed Moon's four levels of reflection by altering the sequence of questions. Italic questions are from the questionnaire of Kember et al. (2000) (1 per level). The other operationalisations are by definitions of level of reflection by Moon 2004, except question 6,15 and 16, which are based on the evaluation criteria of the learning objective of $\mathrm{AC} 3$ : the students can reflect in an academic way on their own design project and design process.

We deliberately skipped the possibility of an answer between B and C in order to force a choice by the assessors. Finally we didn't assume the four levels of reflection to correspond with our division in four papers and regarded the first paper as a kind of a finger exercise. Therefore, we decided to skip the first paper from the research and test the next three on their level of reflection.

The evaluation of the level of reflection of the papers was done by the own AC3supervisor of the students group and a second $\mathrm{AC} 3$ supervisor of another group. So each paper was evaluated by two different evaluators.

Eventually we were interested into what extent it was correct to operationalize the four categories into the questions arranged under these categories. Hence our second research question is: can the operationalisation in our questionnaire of the definitions of reflection derived from theory statistically be confirmed? 
Table 1 Result of reliability analysis

\begin{tabular}{llll}
\hline & $\begin{array}{l}\text { Paper 2 } \\
\mathrm{n}=293\end{array}$ & $\begin{array}{l}\text { Paper 3 } \\
\mathrm{n}=297\end{array}$ & $\begin{array}{l}\text { Paper 4 } \\
\mathrm{n}=296\end{array}$ \\
\hline Cronbach $\alpha$ & 0.94 & 0.94 & 0.95 \\
\hline
\end{tabular}

Table 2 Overview of mean scores for three papers and two evaluators

\begin{tabular}{|c|c|c|c|c|c|}
\hline \multicolumn{2}{|l|}{ Paper 2} & \multicolumn{2}{|l|}{ Paper 3} & \multicolumn{2}{|l|}{ Paper 4} \\
\hline Evaluator 1 & Evaluator 2 & Evaluator 1 & Evaluator 2 & Evaluator 1 & Evaluator 2 \\
\hline$n=129$ & $\mathrm{n}=129$ & $\mathrm{n}=131$ & $\mathrm{n}=131$ & $\mathrm{n}=129$ & $\mathrm{n}=129$ \\
\hline $44.0(9.9)$ & $39.8(10.8)$ & $47.5(9.4)$ & $43.3(10.4)$ & $49.2(9.9)$ & $44.6(11.5)$ \\
\hline
\end{tabular}

\section{Results}

\section{Results for research question 1: Does the level of reflection increases during the course Academic Design Reflection?}

As explained above, the responses to 16 questions were collected. The analyses for the first research question are performed on the composite sum scores, i.e., the general level of reflection. For this purpose, the homogeneity of the composite sum scores is tested, using Cronbach's Alpha. The 16 questions show good homogeneity, as shown in Table 1. Usually, a value for Cronbach's $\alpha$ of 0.70 or higher is considered to reflect a reliable scale. Because of this result, the scores are summed over the responses to the 16 questions.

The mean sumscores for all three measurement points are provided in Table 2 . The dataset of paper 2 includes 293 cases, of which 155 concern the first evaluator and 138 the second evaluator. After deleting cases with only one evaluator, 129 students remain in the dataset, each of which is evaluated by two evaluators (258 cases). The sumscores range from 16 to 64 and the mean score is $41.9(\operatorname{std}=10.5)$.

The dataset of paper 3 includes 297 cases, of which 157 concern the first evaluator and 139 the second evaluator (one is unknown). After deleting cases with only one evaluator, 131 students remain in the dataset (262 cases). The scores range from 20 to 64 and the mean score is $45.4(\mathrm{std}=10.1)$.

The dataset of paper 4 includes 296 cases, of which 153 concern the first evaluator and 142 the second evaluator (one is unknown). After deleting cases with only one evaluator, 129 students remain in the dataset (258 cases). The scores range from 16 to 64 and the mean score is $46.9(\mathrm{std}=11.0)$.

Table 2 shows that the mean sumscores increase between paper 2 and paper 3 and also between paper 3 and paper 4. This points to an increase in the students' level of reflection. What is also shown is a difference in the mean evaluation of the first and the second evaluator. This difference is observed at all three measurement points.

The increase in the mean level of reflection over time can be statistically tested using a repeated measures analysis of variance. This is a statistical test that compares several means when these means have come from the same participants (Field 2013: p 565). In our analysis, the mean sumscores for the students at the three measurement points are compared. This is called the "within-subjects" factor. We also included a variable in the 
Table 3 Overview of mean scores for three papers and two evaluators for students without missing observations $(\mathrm{n}=100)$

\begin{tabular}{|c|c|c|c|c|c|}
\hline \multicolumn{2}{|l|}{ Paper 2} & \multicolumn{2}{|l|}{ Paper 3} & \multicolumn{2}{|l|}{ Paper 4} \\
\hline Evaluator 1 & Evaluator 2 & Evaluator 1 & Evaluator 2 & Evaluator 1 & Evaluator 2 \\
\hline $45.1(10.1)$ & $39.7(10.4)$ & $48.3(9.8)$ & $42.8(11.0)$ & $50.1(10.0)$ & $43.6(11.6)$ \\
\hline
\end{tabular}

Fig. 2 The increase of level of reflection in subsequently paper 2, 3 and 4 for both evaluators for students without missing observations $(n=100)$

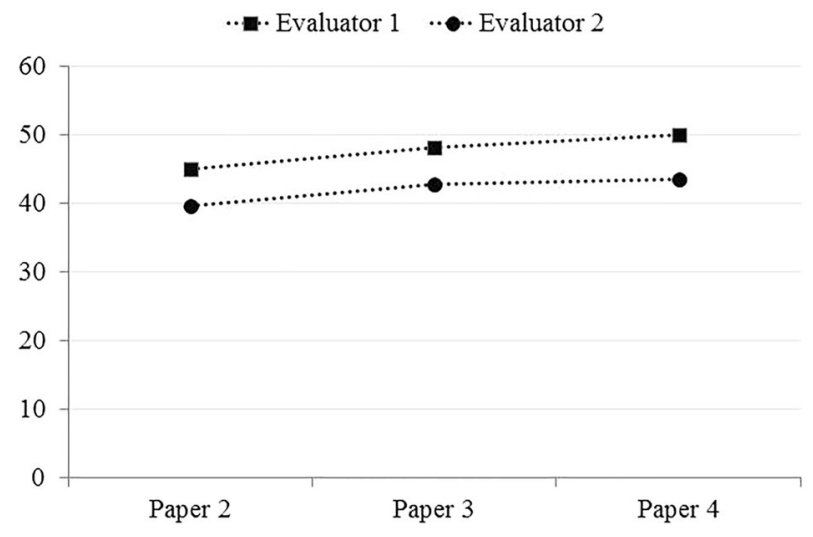

analysis that indicated whether the sumscore was calcaluted for the first or for the second evaluator. This is called the "between-subjects" factor. For the examination of the scores over time it is important that only students are selected that have observations for both evaluators at each one of the three measurement points. This applies to 100 students.

The results for the 100 students are provided in Table 3 and in Fig. 2. The results resemble the results described above for the total data set. The table shows that the mean sumscore increases over time. This result is supported by the repeated measures anova that shows that the mean sumscore differs statistically significantly over time $(p<0.01)$. Furthermore, the table shows that the mean sumscore is higher for the first evaluator than for the second evaluator on each of the three measurement points. This effect is also statistically significant $(p<0.01)$. Finally, there is no interaction effect between time and evaluator $(p=0.48)$. This means that both first and second evaluator show a similar increase in mean scores over time. This can be clearly seen from Fig. 2.

Based on Table 3 the total average of the level of reflection of the papers on a scale from 16 minimum to 64 maximum is 44.9 .

Answering the first research question 'Does the level of reflection increases during the course Academic Design Reflection?' we conclude there is a statistically significant but slight increase of the level of reflection. Further we conclude that the scores of the first evaluator, who was also the supervisor of the student, are slightly higher than the more 'neutral' second evaluator. A statistical analysis of the differences in the average level of reflection between all groups of students was unjustified because all the groups were too small.

Finally we wanted to show the results of the analysis on the frequency of the scores $(1$, 2, 3 and 4) related to the classification that we made in four groups of questions: Descriptive Writing, Reflective Writing, Dialogic Reflection and Critical Reflection (see Fig. 1). 
Table 4 Cronbach reliability scores for the four categories

\begin{tabular}{llll}
\hline Cronbach $\alpha$ & $\begin{array}{l}\text { Paper 2 } \\
\mathrm{n}=293\end{array}$ & $\begin{array}{l}\text { Paper 3 } \\
\mathrm{n}=297\end{array}$ & $\begin{array}{l}\text { Paper 4 } \\
\mathrm{n}=296\end{array}$ \\
\hline Habitual action/descriptive writing & 0.84 & 0.83 & 0.84 \\
Understanding/descriptive reflection & 0.77 & 0.79 & 0.82 \\
Reflection/dialogic reflection & 0.79 & 0.80 & 0.84 \\
Critical reflection/critical reflection & 0.79 & 0.75 & 0.78 \\
\hline
\end{tabular}

The frequency of the scores related to the separate questions is statistical normal, meaning that the distribution shows a high frequency of the middle scores 2 and 3 and a low frequency of the extreme scores 1 and 4.

\section{Results for research question 2: Can the operationalisation in our questionnaire of the definitions of reflection derived from theory statistically be confirmed?}

For the second research question we explored whether the four levels of reflection that we adapted from the models by Kember et al. (2000) and Moon (2004: p. 96, 97) could be confirmed in our dataset. This concerns the levels: Descriptive Writing, Reflective Writing, Dialogic Reflection and Critical Reflection (see Fig. 1). We used Cronbach's Alpha to determine the reliability of the various levels, followed by a Principal Component Analyis (PCA) to check the assumed pattern of four different levels of reflection.

The results of the Cronbach's Alpha test are presented in Table 4. Taking into account that a scale is judged to be reliable when the coefficient for Cronbach's Alpha is at least 0.70 , all levels of reflection can be considered to have sufficient internal consistency.

To further falsify the validity of the division into four levels we executed an explorative factor analysis, i.e., Principal Components Analysis (PCA). A PCA is a statistical method that can be used to understand the structure of a set of variables (Field 2013, p. 666). It means that we examined which pattern is prevalent in the sixteen responses to the questions. Responses to questions that highly correlate with each other form a "factor". Multiple factors can be established. We performed the PCA for each of the three papers, including only cases for which two observations were present. The Varimax rotation method was used. This means that we obtained factors that are independent of each other and that are relatively easy to interpret (Field 2013, p. 681).

The results showed that for all three measurement points, two factors could be discerned. Together these factors explain 61 (paper 2), 62 (paper 3) and 66 (paper 4) percent of the variance, which is a good result. The items that primarily and consistently load on one of the two factors are question: 1, 2, 3, 11, 14 and 16. This means that these items correlate relatively high with each other. The items relate to "evidence of reflection", "understanding of the concepts of lectures, module manual and literature", "the paper shows a backtrack", "reflected to see if there can be learned", "integration of lectures, module manual and literature" and "establishment of an argued individual position". We read the descriptions of the six items carefully to search for a common underlying theme. However, we did not find such a theme. Furthermore, an inspection of these six items shows that they theoretically belong to all four different levels of reflection.

The items that primarily and consistently load on the other factor are question: 4, 6, 9 and 10. Two of these items ("no discussing reflection" and "most reflection is from one perspective") theoretically belong to the same level of reflection, i.e., the 
Understanding/Descriptive reflection level. The other two items ("consciousness that acts and events are localized in and influenced by multiple historical and socio-political contexts" and "follows what is required") belong to different levels. Again, we do not believe that these four items reflect an underlying common theme.

The other questions did not show consistent results; they sometimes showed the highest loading on the one factor and sometimes on the other factor.

Our results differ from the four factor-structure as hypothesized based on the theory of Moon (2004). First, our results pointed consistently to only two factors instead of four. Besides from that, the questions that made up the two factors differed from what was expected on the basis of the theory by Moon (2004) and the previous study by Kember et al. (2000). Moreover, we were unable to explain the results of the PCA, meaning that we could not find a theoretical or logical explanation for the supposed relationships between the items belonging to each one of the factors. Apparently, in this case, the operationalisations of Moon's definitions and the operationalisations of the learning objectives of the course, do not match statistically with the classification of Moons and Kember et al.

So answering our second research question 'Can the operationalisation in the questionnaire of the definitions of reflection derived from theory statistically be confirmed?' we conclude that our model of classification is not statistically confirmed in the data.

The results from the Cronbach's Alpha test and the PCA seem contradictory as quite reliable results were found with the first method, but the underlying structure could not be confirmed using PCA. We believe that this finding might be explained by the fact that all items show relatively high intercorrelations. This can also been seen from the high value of Cronbach's Alpha of 0.94/0.95 that we presented for all sixteen items examined at once. Seen from a qualitative point of view, the setup of the questionnaire seems sensible, however not supported by statistical analysis. We assume that the multi interpretability of the questions plays an important role in this. Further research e.g. a test on the difference in interpretation of the questions by asking the evaluators to group the several questions into each of the four levels of reflection instead of giving it in advance, could provide insight.

\section{Conclusions and implications}

\section{Conclusions}

Our research object was our Bachelor course in Academic Design Reflection. Two research questions were at hand: (1) does the level of reflection increase during our course and (2) Can the operationalisation in our questionnaire of the definitions of reflection derived from theory statistically be confirmed? The research shows that the average level of reflection of the students papers increases per successively paper and that the total average level of reflection of the papers is sufficient,. Further, we conclude that de scores of the first evaluator, who was also the supervisor of the student, are slightly higher than the more 'neutral' second evaluator. Finally the research shows that the classification of the questionnaire into four groups of questions with an ascending reflection level is not supported by statistical analysis, the model doesn't fit the data, contrary to expectations based on literature. Further research is therefore required, but we already can say a number of things about the implications for our design education. 


\section{Implications for design education}

Many of the TU Delft fields of engineering and design, such as architecture and the built environment, are positioned in the heart of the so called 'practical sciences' (Klaasen 2004; Rooij and Frank 2016) or 'engineering sciences' (Kamp 2016a, b). Today's and tomorrow's complex socio-technical challenges in the built environment, such as sustainable, resilient, fair and healthy spatial development need well considered and integrated (design) solutions. These challenges are the backbone, the rationale and the motivation behind our Architecture \&Built Environment academic sub disciplines and our curriculum specialisation tracks, such as architecture, urbanism, landscape architecture, building technology, and management in the built environment. The main knowledge question in our field therefore focuses to a large extent on 'does it work?' (e.g. a design, a plan, a solution proposal, a strategy) in contrast to empirical sciences which-via the construction of theories and the formulation of hypotheses-focus on the knowledge question 'is it true?'.

This specific nature of built environment engineering education requires a specific set of academic design skills in order to (be able to) assess whether or not designs 'work'. Important umbrella-skills are related to:

1. the critical assessment of design situations,

2. the creative development of meaningful design alternatives,

3. the thorough ex-ante evaluation of the design products,

4. the andante evaluation of dynamic design processes,

5. positioning yourself as designer and your design work in the academic and professional debate, and

6. relating design to (methods of) scientific research.

There is a call and a need from both inside and outside the faculty to significantly improve the academic skills of design students. At the Delft faculty of Architecture and the Built Environment this is for example apparent from quality assurance programmes (e.g. student questionnaires), dialogues with student bodies (e.g. student council and study association, Stylos) and the Board of Studies. ${ }^{1}$ While students learn a lot from the current curricula, they also see room to raise the academic bar substantially. Teaching staff expresses similar views in education evaluation reports. The 2012 QANU visitation committee and the 2017 (self-organised) external audit committee advised the faculty to make better use of the academic design environment (defining it as a missed potential).

Students learn design best by doing-like most skills are learned best by doing them over and over again. But design might be understood better by academic reflection.

We showed that there is significant room for improvement for our bachelor design students. But this also holds for our master students. The faculty is convinced that such an academic reflection skills programme will only be successful, when it is closely related to, or even better, fully integrated into the design projects.

The A\&BE faculty already works with a line of actions to evaluate, discuss and improve the academic skills programmes of our design curricula. Two key actions are relevant to present here. First. We are developing a (bilingual) book on Academic skills for architects

\footnotetext{
1 In the 2017 national student questionnaire (NSE) A\&BE bachelor and master students value 'academic skills' with a score of 3.4 (B.Sc.) and 3.5 (M.Sc.) out of 5, which illustrates the potential for improvement.
} 
('Academische vaardigheden voor bouwkundigen') which will explicitly set the exit level of our undergraduate programme and at the same time the entrance level of our master (design) curricula. The idea is that the book will support the undergraduate students during their full 3 year bachelor programme. And it will not only be relevant for our students, but also a help for our design mentors as many of them-we work with a large body of design teachers from practice-explicitly ask for guidance in teaching academic skills and in particular design reflection. Second. We are redeveloping the academic skills programme of our 2 year master curriculum Architecture: both the first year research methods and/or methodology courses and the second year graduation project. For example: all final thesis students developing designs are asked to write a number of small papers reflecting on their graduation project during the year. They are assessed by the full mentor team, including the so called external examiner representing the faculty board of examiners. The structure is in place but still quite some work needs to be done for a fruitful delivery.

\section{Implications for further research}

We believe the total average score of reflection can be improved. We assume a higher level of reflection skills is both possible and desirable for our student body. We dedicate an important role to the teachers. The supervisors who take care of the reflection-education now in our course, are design supervisors who have had to learn reflection themselves as in their graduation training only minor attention was paid to their reflection skills. They would, however, be better trained in reflective thinking itself, but also as part of reflection in action. That should give the concept of reflection more depth and make it more clear for them. Instead of the out of educational considerations fairly simple definition of ' thinking about your own work ' that we have used here, in particular, more attention should be given to '(re)considering' because ' reflection on action ' after all is about looking back.

Even though the division into groups of level of reflection is not statistically supported, yet, we will still use this division, based on Moon (2004) for educational reasons. It makes clear to students there are different levels of reflection, in a way that seems to appeal to our students. The idea of getting more distance in a metaphorical sense or an ascending abstraction in the contemplation of one's own work, in this case the own design, seems at least to trigger students to " loosen up ' of their work, making them better able to oversee their work, in our opinion a necessity for reflection.

Finally, in the foregoing we ignored the question of the extent to which the skill to reflect leads to better designs. However, at this moment in our faculty a survey is conducted with the question of what is the view of students about the contribution of reflection to their design skills. It goes without saying that this is a very limited question, but it is a start for future research.

Open Access This article is distributed under the terms of the Creative Commons Attribution 4.0 International License (http://creativecommons.org/licenses/by/4.0/), which permits unrestricted use, distribution, and reproduction in any medium, provided you give appropriate credit to the original author(s) and the source, provide a link to the Creative Commons license, and indicate if changes were made.

\section{References}

Argyris, C. (1977). Double loop learning in organizations, Harvard Bussiness Review, September-Oktober. 
Boekholt, J. (1984). Bouwkundig ontwerpen: een beschrijving van de structuur van bouwkundige ontwerpprocessen Dissertation, Eindhoven University of Technology.

Boud, D., \& Garrick, J. (1999). Understanding learning at work. London: Routledge.

Brockbank, A. (1989)/2007 2nd version of 'Facilitating in reflective learning in higher education' with Ian McGill.

Brockbank, A., McGill, I. [1998]/2007 Facilitating in reflective learning in higher education. Bristol: Taylor $\&$ Francis.

Cowan, J. (2006). On becoming an innovative university teacher. Maidenhead: Open University Press.

Dewey, J. (1933) Philosophy and Civilazation. Philosophy, 8(31), 360-361.

Field, A. (2013). Discovering statistics using IBM SPSS statistics (4th ed.). London: Sage.

Fry, H., Ketteridge, S., \& Marshall, S. (2003). A handbook for teaching \& learning in higher education. London: Kogan Page Limited.

Kamp, A. (2016a). Engineering education in a rapidly changing world. Delft: Delft University of Technology.

Kamp, A. (2016b). Engineering education in a rapidly changing world. Rethinking the vision for higher engineering education. Second Revised Edition. Delft University of Technology, 4TU Cenre for Engineering Education.

Kember, D., Leung, D. Y. P., Jones, A., Loke, Y. A., McKay, J., Sinclair, K., et al. (2000). Development of a questionnaire to measure the level of reflective thinking. Assessment \& Evaluation in Higher Education, 25(4), 381-395.

Klaasen, I. T. (2004). Knowledge-based design: Developing urban \& regional design into a science. (PhD thesis), Technische Universiteit Delft, Delft.

Kolb, D. A. (1984). Experiential learning: Experience as the source of learning and development. Englewood Cliffs, NJ: Prentice Hall.

Mann, K., Gordon, J., \& MacLeod, A. (2009). Reflection and reflective practice in health professions education: A systematic review. Advances in Health Sciences Education, 14, 595-621.

Mittendorff, K. (2014). Leren reflecteren. In F. Meijers, M. Kuijpers, K. Mittendorff, \& F. Wijers (Eds.), Het onzekere voor het zekere. Kwetsbaarheid als kracht in loopbaandialogen. Antwerpen/Apeldoorn: Garant.

Moon, J. A. (2004). Handbook of reflective \& experiential learning: Theory and Practice. London: Routledge Falmner.

Ojiako, U., Johansen, E., Edum-Fotwe, F., \& Greenwood, D. (2008). Facilitating the development of project managers as reflective and creative practitioners. Northumbria Working Paper Series: Interdisciplinary Studies in the Built and Virtual Environment, 1 (1). pp. 67-74.

Rooij, R., \& Frank, A. (2016). Educating spatial planners for the age of co -creation: The need to risk community, science and practice involvement in planning programmes and curricula. Planning, Practice \& Research, 31(5), 473-485.

Roozenburg, N. F. M., \& Dorst, K. (1998). Describing design as a reflective practice: Observations on Schon's theory of practice. In E. Frankenberger, P. Badke-Schaub, \& H. Birkhofer (Eds.), DesignersThe key to successful product development. London: Springer.

Sage, D., Dainty, A., \& Brookes, N. (2010). A consideration of reflexive practice within the critical projects movement. International Journal of Project Management, 28, 539-546.

Schön, D. (1982). The reflective practitioner: How professionals think in action. New York: Basic Books.

Schon, D. A. (1987). Educating the reflective practioner: Toward a new design for teaching and learning in professions. Jossey-Bass higher education series. San Francisco.

Simon, H. A. (1969). The sciences of the artificial. Cambridge, MA: MIT Press.

Van Dooren, E., Boshuizen, E., van Merriënboer, J., Asselbergs, T., \& van Dorst, M. (2014). Making explicit in design education: Generic elements in the design process. International Journal of Technology and Design Education, 24(1), 53-71.

van Dooren, E., van Merriënboer, J., Boshuizen, H., van Dorst, M., \& Asselbergs, T. (2017). Architectural design education: In varietate unitas. International Journal of Technology and Design Education, 28, 431-449

van Doorn, A. (2004). Ontwerp/process. Amsterdam: SUN.

Publisher's Note Springer Nature remains neutral with regard to jurisdictional claims in published maps and institutional affiliations. 